\title{
Da resistência à violência de Estado a um novo projeto de formação nacional: genealogias das políticas de Direitos Humanos no Brasil
}

\section{Kelly Silva}

\section{(2) OpenEdition \\ Journals}

Edição electrónica

URL: http://journals.openedition.org/aa/638

DOI: $10.4000 /$ aa. 638

ISSN: 2357-738X

Editora

Programa de Pós-Graduação em Antropologia Social (UnB)

Edição impressa

Data de publição: 1 junho 2014

Paginação: 39-71

ISSN: 0102-4302

Refêrencia eletrónica

Kelly Silva, «Da resistência à violência de Estado a um novo projeto de formação nacional: genealogias das políticas de Direitos Humanos no Brasil», Anuário Antropológico [Online], v.39 n.1 | 2014, posto online no dia 01 outubro 214, consultado o 28 abril 2021. URL: http:// journals.openedition.org/aa/638 ; DOl: https://doi.org/10.4000/aa.638

Este documento foi criado de forma automática no dia 28 abril 2021.

\section{$\Theta \oplus \Theta \Theta$}

Anuário Antropológico is licensed under a Creative Commons Atribuição-Uso Não-Comercial-Proibição de realização de Obras Derivadas 4.0 International. 


\title{
Da resistência à violência de Estado a um novo projeto de formação nacional: genealogias das políticas de Direitos Humanos no Brasil
}

\author{
Kelly Silva
}

\section{NOTA DO EDITOR}

Recebido em: 09/04/2014

Aceito em: 20/06/2014

1 Este artigo tem como objetivo identificar a genealogia das políticas de Estado de direitos humanos no Brasil e os modos pelos quais tais políticas, em sua primeira expressão, implicavam também a proposição de um novo projeto de formação nacional. Para tanto, tomo como objeto de análise o I Programa Nacional de Direitos Humanos (I PNDH), lançado pelo governo Fernando Henrique Cardoso em maio de 1996. Situa-se tal genealogia em duas escalas de análise, que se sobrepõem. Em uma primeira dimensão, a concepção e a execução do I PNDH parecem ser resultado de táticas internacionais de atuação política do Estado brasileiro na Nova República, pelas quais ele procurava acumular capital simbólico a fim de ser reconhecido como um global player. Em uma segunda escala, a do espaço nacional, argumenta-se que o conteúdo do I PNDH, que priorizava os direitos civis e políticos, o combate à violência de Estado, bem como políticas de correto reconhecimento, expressava, em parte, as trajetórias institucionais de atuação do coletivo de pessoas envolvido em sua concepção e os compromissos políticos daí derivados. ${ }^{1}$ Dentre tais compromissos, destacam-se os laços construídos com a Igreja Católica na resistência contra a ditadura militar. Argumento também que o I PNDH foi um evento crítico na promoção de políticas de ação afirmativa e de 
valorização da diversidade cultural no Brasil contemporâneo, as quais colocam em xeque o mito da democracia racial e da miscigenação como ideal político e cultural.

2 No âmbito deste artigo, tomo a categoria direitos humanos como uma categoria de governo e como um mobilizador político polissêmico, manejada por diferentes atores para o alcance de diversos fins. Não me apoio, portanto, em nenhuma preconcepção substantivista ou normativa a seu respeito. Procuro, antes, compreender seus significados e vida social em sua trajetória concreta na gênese das políticas de Estado em prol dos direitos humanos no Brasil e os efeitos políticos desejados e derivados desse processo.

3 Entre outras, tomo por inspiração para as análises empreendidas neste artigo as premissas metodológicas apresentadas por Wolf $(1974,2001)$ e Elias $(1999,2006)$ no que concerne ao modo de se elaborar certa antropologia das instituições e das sociedades complexas. Ambos nos advertem que por detrás dos aparelhos formais de poder existem redes informais - pessoais e institucionais - que os conformam e os fazem funcionar. ${ }^{2}$ Por isso, sublinham os autores citados, para se tecer uma compreensão adequada destas sociedades é preciso atentar para as redes sociais por meio das quais elas próprias se constituem. No que diz respeito à fenomenologia do poder, apoio-me também nos legados de Foucault (2000), que sugerem que o poder se manifesta de forma ascendente - da periferia para o centro - capilar, em rede e a partir de seus efeitos. Taylor (1994) e Cardoso de Oliveira (2007) são outros interlocutores importantes na sustentação do argumento de que, em seus primórdios, a política nacional de direitos humanos era também uma política de correto reconhecimento.

$\mathrm{O}$ artigo segue estruturado em três seções. Na primeira, discuto de modo sintético os processos que levaram à formulação do I PNDH e as características de seu conteúdo. Ao buscar a genealogia do programa, inscrevo-a no complexo institucional conformado pela Comissão Pontifícia de Justiça Paz em São Paulo, a Comissão Teotônio Vilela e o Núcleo de Estudos da Violência (NEV) da Universidade de São Paulo enas pessoas que nele circularam durante o período da ditadura no Brasil e além dele. Ainda nesta primeira parte chamo a atenção para o protagonismo da Igreja Católica e outras instituições confessionais na articulação da sociedade civil em prol dos direitos humanos no Brasil.

5 Na segunda seção do texto, analiso parte das políticas propostas no I PNDH, sob a rubrica de proteção do direito ao tratamento igualitário perante a lei, particularmente aquelas voltadas à população negra e àspopulações indígenas. Argumento que tais políticas colocam em xeque a miscigenação como ideal político e cultural de formação nacional, bem como o mito da democracia racial.

6 Por fim, na terceira parte do texto, procuro extrair implicações cognitivas do que resultou da controvérsia entre instituições envolvidas na formulação do programa e entidades como o Grupo Gay da Bahia e a Associação Brasileira de Gays, Lésbicas e Travestis (ABGLT): a exclusão do conteúdo do programa de políticas públicas direcionadas a homossexuais. Correlaciono tal fato às alianças que o grupo responsável pela concepção do programa tinha com a Igreja Católica e outros atores com tendências mais conservadoras. Com base em tal controvérsia e nos dados analisados ao longo do texto, argumento que implicada na primeira política de Estado de direitos humanos estava também uma política de correto reconhecimento. Nas considerações finais, retomo de forma sintética os argumentos apresentados ao longo do artigo, ao mesmo 
tempo em que arrisco a proposição de uma nova escala interpretativa para parte dos fenômenos discutidos, a qual, contudo, só poderá ser respondida no futuro.

7 Os dados analisados no âmbito deste artigo foram produzidos entre os anos 1998 e 2000, mediante trabalho de campo, análise documental e entrevistas com atores envolvidos na formulação e na execução do I PNDH, então localizados, sobretudo, no Ministério da Justiça e no Núcleo de Estudos de Violência da Universidade de São Paulo. Ao disponibilizar parte importante da documentação que permitiu constatar a exclusão das demandas de políticas públicas direcionadas a gays, lésbicas e travestis do I PNDH, o antropólogo Luiz Mott, então secretário para Direitos Humanos da Associação Brasileira de Gays Lésbicas e Travestis e professor da Universidade Federal da Bahia, foi também um interlocutor fundamental para a construção dos argumentos explorados a seguir. ${ }^{3}$ Expresso minha gratidão a todos estes interlocutores, cuja boa vontade e disposição ao diálogo permitiram a elaboração das hipóteses interpretativas que seguem.

\section{Origens institucionais da política estatal de direitos humanos no Brasil}

8 A concepção e a execução do I Programa Nacional de Direitos Humanos podem ser compreendidas como efeitos de eventos que ocorreram em duas escalas de análise diferenciadas, mas que passam a se sobrepor como produto da trajetória de alguns atores sociais e de certas dinâmicas institucionais. Em uma primeira escala, a elaboração do I PNDH é produto da crescente adesão do Estado brasileiro a instituições e dispositivos de governança global no contexto da redemocratização do país, tendo como marco a Constituição de 1988. A partir do governo José Sarney, o Brasil tornou-se progressivamente signatário de uma série de pactos e declarações internacionais, com implicações vinculadoras que impunham, muitas vezes, a formulação de dispositivos de governo que promovessem a internalização nacional dos mesmos. Por meio de tais adesões, o Estado brasileiro, entre outras coisas, cultivava uma mudança da imagem do país no cenário global - afirmando seu caráter de república democrática - ao mesmo tempo em que ia se constituindo como um global player.

9 No âmbito de tais iniciativas, destaca-se a participação do Brasil na Conferência Mundial de Direitos Humanos em Viena, em 1993, liderada pelo então chanceler Fernando Henrique Cardoso, no governo de Itamar Franco. Em 25 de junho de 1993 o Brasil tornou-se signatário da Declaração e Programa de Ação de Viena, que sugeriram, entre outros pontos, que os governos e os Estados formulassem um programa nacional de direitos humanos para proteção e promoção desses direitos. Após a Conferência, o então Ministro da Justiça, Maurício Corrêa, convocou uma comissão formada por entidades governamentais e não governamentais que, funcionando através de grupos de trabalho, tinha por objetivo formular uma agenda nacional de direitos humanos. As discussões realizadas por esta comissão deram origem ao Programa Nacional de Combate à Violência.

10 A chegada de Fernando Henrique Cardoso (FHC) à Presidência da República, junto com algumas das forças políticas por ele representadas, criou ainda melhores condições para a construção de uma política nacional de direitos humanos. Uma vez no poder, Fernando Henrique Cardoso e outros atores políticos alçados a posições-chave do Poder Executivo, no que diz respeito à área da Justiça, tinham uma longa trajetória de ação política em prol dos direitos humanos. Esta trajetória dizia respeito, sobretudo, ao 
combate ao uso arbitrário da violência por parte do Estado e do desrespeito aos direitos civis e políticos no Brasil no contexto da ditadura. Dentre tais atores, destaca-se a figura de José Gregori, primeiramente chefe de gabinete do ministro da Justiça, Nelson Jobim, e a seguir secretário de Estado de Direitos Humanos, entre abril de 1997 e junho de 2000, e ministro da Justiça, entre abril de 2000 e novembro de 2001.

11 Não por acaso, atribui-se à Lei 9.140/95, que prevê e regula a indenização às famílias de desaparecidos políticos à época do regime militar, a primeira grande iniciativa em prol da promoção dos Direitos Humanos no governo FHC. Foi, no entanto, em seu discurso de 7 de setembro de 1995, que o então presidente assumiu o compromisso público de elaborar um programa de direitos humanos, como um dispositivo de governo voltado à promoção da democratização da sociabilidade nacional. Tal política foi justificada como forma de afrontar e superar, em longo prazo, a desigualdade, o racismo e várias outras formas de discriminação. Este discurso é digno de nota por seu caráter excepcional, que coloca em xeque e suspensão o mito da democracia racial. Estimulando a organização da sociedade civil em defesa de seus direitos, o presidente afirmou a necessidade de se lutar:

[...] em defesa também da igualdade, em que as diferenças de sexo, gênero não sejam impeditivas da realização dos potenciais da pessoa humana. A luta pelo respeito nas diversas fases da vida, da criança até o mais idoso, a luta para que os portadores de deficiência física sejam tratados condignamente, como têm direito, e com respeito. A luta contra a discriminação do índio, do negro, mormente agora, que nós estamos, nesse ano, também, para comemorar os 300 anos de Zumbi. Nós temos que afirmar, com muito orgulho mesmo, a nossa condição de uma sociedade plurirracial e que tem muita satisfação de poder desfrutar desse privilégio de termos, entre nós, raças distintas e, de termos também tradições culturais distintas. Essa diversidade que faz, no mundo de hoje, a riqueza de um país. [...] (Brasil, Presidência da República, 1995:8, 10-1).

Com o objetivo de formular o que veio a ser o I PNDH, formou-se no âmbito do Ministério da Justiça uma Coordenadoria do Plano Nacional de Direitos Humanos (CPNDH), dirigida por José Gregori, então chefe de gabinete do ministro da Justiça. Por meio da CPNDH, o Ministério da Justiça estabeleceu um convênio com o Núcleo de Estudos da Violência (NEV) da Universidade de São Paulo a fim de, em parceria, elaborarem o Plano Nacional de Direitos Humanos (PNDH).

O I Programa Nacional de Direitos Humanos (I PNDH) foi construído a partir de um processo de consulta à sociedade civil organizada, executado por meio da realização de seminários em todo o país, bem como mediante troca de correspondências entre a entidade responsável pela formulação do pré-projeto do PNDH, o NEV, e instituições que se apresentavam à época, 1995, como defensoras de direitos humanos. A intenção desse processo de consulta era obter indicações dos tipos de políticas públicas que o governo deveria engendrar para a promoção dos direitos humanos no país. Ao todo, tomaram parte nos processos de consulta para a elaboração do I PNDH 334 pessoas, representantes de 210 entidades. Para o recolhimento dessas indicações, realizaram-se também seis seminários em todo o país, organizados através de parceria do NEV com entidades regionais (organizações não governamentais e entidades governamentais) nas seguintes cidades: São Paulo, Rio de Janeiro, Recife, Belém, Natal e Porto Alegre. A partir da sistematização das sugestões apresentadas, o NEV elaborou um primeiro rascunho do que viria a ser o I PNDH e submeteu-o à I Conferência Nacional de Direitos Humanos, realizada pela Câmara dos Deputados em abril de 1996. A Comissão de 
Direitos Humanos da Câmara dos Deputados, criada em 1995, teve preeminência na organização deste evento, e era liderada, à época, pelo deputado Hélio Bicudo.

O programa foi apresentado à sociedade em 13 de maio de 1996, data em que se celebra a memória da abolição da escravatura no Brasil. Nessa mesma ocasião, o governo também indenizou a primeira família de um desaparecido político, assumindo como de responsabilidade do Estado muitos dos assassinatos e desaparecimentos ocorridos durante o regime militar no Brasil.

O I PNDH abrigava um conjunto de 228 propostas de ações governamentais a serem executadas em curto, médio ou longo prazo, das quais algumas foram formuladas para implementação em parceria com a sociedade civil. ${ }^{4}$ Tais ações, de forma geral, visavam promover o respeito aos direitos civis e políticos e ações de proteção contra o uso arbitrário da violência pelo Estado. As ações programáticas estavam organizadas em seis grandes frentes: proteção do direito à vida; proteção do direito à liberdade; proteção do tratamento igualitário perante a lei; educação e cidadania; ações internacionais para proteção e promoção dos direitos humanos; implementação e monitoramento do PNDH. Havia também referências residuais aos chamados direitos sociais, econômicos e culturais e aos direitos coletivos. ${ }^{5}$ A maior ênfase sobre os direitos civis e políticos deu-se, segundo Pinheiro (1997), em função de reconhecer-se que grande parte das violações de direitos humanos no país, sobretudo o uso arbitrário da força pelo Estado, era resultado da falta de consciência e vivência do direito à vida, à liberdade e à igualdade por parte da maioria da população. Vejamos alguns exemplos das ações propostas:

Proteção do Direito à vida

$[\ldots]$

Promover a elaboração do mapa da violência urbana, com base em dados e indicadores de desenvolvimento urbano e qualidade de vida, a partir de quatro grandes cidades; [...]

Proteção do Direito à liberdade

[...]

Fortalecer os mecanismos para fiscalizar e coibir o trabalho forçado, com vista à eficácia do Programa de Erradicação do Trabalho Forçado e do aliciamento de trabalhadores - PERFOR, criado pelo decreto de 03 de setembro de 1992 [...] (Brasil/ Ministério da Justiça, 1998).

16 Argumento, contudo, que a ênfase nos direitos civis e políticos característica do I PNDH é resultado de outros fatos sociais, além daquele exposto por Pinheiro. Por um lado, deve-se à história da mobilização dos direitos humanos contra as arbitrariedades do Estado no contexto da ditadura no Brasil pelos atores que mais tarde protagonizaram sua institucionalização enquanto política de Estado, a partir de 1994. De outro lado, tal

ênfase é consequência dos constrangimentos políticos existentes dentro do próprio governo no primeiro mandato de FHC.

17 Como relatei acima, a formulação da proposta do I PNDH foi atribuída ao NEV que, à época, tinha Paulo Sérgio Pinheiro como um de seus principais dirigentes. Entre os quadros do NEV figuravam, entre outros, intelectuais que também atuaram em conjunto na Comissão Teotônio Vilela em prol da defesa dos direitos humanos dos presos comuns e de pessoas reclusas em instituições fechadas. A forma pela qual o NEV dá sentido à sua origem vincula-o genealogicamente à Comissão Teôtonio Vilela e ao grupo de intelectuais que nela atuava, dos quais muitos tiveram papel importante na 
institucionalização das políticas de Estado em prol dos direitos humanos. Na página eletrônica do NEV encontramos a seguinte narrativa a respeito de suas origens:

Historicamente, a atividade de intervenção para a proteção dos direitos humanos antecedeu a atividade de pesquisa científica desenvolvida pelo NEV. Seu surgimento está vinculado ao trabalho desenvolvido pela Comissão Teotônio Vilela. A Comissão nasceu em 1982, de um grupo criado pelo senador Severo Gomes para investigar um massacre que ocorrera no hospital psiquiátrico em Franco da Rocha. Entre seus membros fundadores do grupo estavam o padre Agostinho Duarte de Oliveira, Antonio Candido, Fernando Gabeira, Fernando Millan, Helio Bicudo, Jose Baptista Breda, José Gregori, Paulo Sérgio Pinheiro e o senador Teotônio Vilela. Após visitas a Franco da Rocha, à Casa de Custódia e Tratamento de Taubaté e a celas de distritos policiais em Campinas, Severo Gomes propôs, em 1983, que o grupo se transformasse numa comissão e que se chamasse Teotônio Vilela, uma homenagem ao senador que, ao final da ditadura militar, presidiu a comissão sobre anistia no Congresso Nacional, dando início ao trabalho de combate às violações praticadas em instituições totais, especialmente o sistema penitenciário, instituições para crianças e adolescentes e asilos para doentes mentais.

Durante a atividade de militância, Severo Gomes e o grupo perceberam a necessidade de ser desenvolvido um trabalho de pesquisa em paralelo e, em 1985, por intermédio de Paulo Sérgio Pinheiro, inicia-se o processo de criação de um centro de pesquisas sobre criminalidade e direitos humanos na Universidade de São Paulo, nos moldes do Center for the Study of Human Rights, da Universidade de Columbia. Com a possibilidade de criação de núcleos de apoio à pesquisa na universidade ao final dos anos 80 e com a parceria do professor do Departamento de Sociologia, Sérgio Adorno, em 1987 é então criado o Núcleo de Estudos da Violência, vinculado à Pró-Reitoria de Pesquisa da USP. Atualmente, os dados produzidos pelas pesquisas desenvolvidas no NEV servem de subsídio também para o trabalho de intervenção da Comissão Teotônio Vilela. (Em: http://www.nevusp.org/portugues/index.php?

option=com_content\&task=view\&id=4\&Itemid=4. Acesso em: 03/05/2014).

Criada em 1982, a gênese da Comissão Teotônio Vilela é retratada por alguns como efeito de articulações e fatos políticos relacionados às dinâmicas do próprio regime militar no Brasil (Tsunoda, 2012:42). José Carlos Dias, ex-ministro da Justiça no governo FHC e ex-presidente da Comissão, por exemplo, na conferência Que justiça sem direitos humanos?, apresentada na Universidade de Brasília em 1999, sugeriu que o aprisionamento de membros das elites intelectuais e políticas que faziam oposição ao regime militar fez com que viessem a testemunhar as privações ilegítimas de direitos humanos elementares nas delegacias e nos presídios no país. Tais experiências teriam permitido a constatação de que a reclusão, no Brasil, não era somente uma pena de privação de liberdade. Uma vez libertados, parte desses ex-presos políticos se engajaram na defesa dos direitos humanos dos presos comuns. ${ }^{6}$

No entanto, faziam também parte da Comissão Teotônio Vilela muitos daqueles que atuaram na Comissão de Justiça e Paz (CJP) de São Paulo, fundada em 1973, cuja agenda, até 1985, estava centrada na defesa dos direitos civis dos presos políticos no contexto da ditadura no Brasil. Dentre os atores políticos que vieram a circular entre duas ou três destas instituições, quais sejam, Núcleo de Estudos da Violência, Comissão Justiça e Paz e Comissão Teotônio Vilela, mesmo que em temporalidades diferentes, destacamse, para efeitos desta análise: Paulo Sérgio Pinheiro, Sérgio Adorno, José Carlos Dias, José Gregori, José Serra, Hélio Bicudo, Margarida Bulhões Pereira Genevois, Dalmo Dalari, Fernando Henrique Cardoso, entre outros. Todos eles tiveram papéis 
importantes no processo de institucionalização da defesa e da promoção dos direitos humanos enquanto política de Estado no Brasil, bem como nas partes que compõem o complexo institucional que os vinculou em rede. ${ }^{7}$

Quando questionado em 1999 a respeito da gênese de sua trajetória em defesa dos direitos humanos, José Gregori conectava-a imediatamente à sua atuação junto à Comissão Pontifícia de Justiça e Paz em São Paulo (Silva, 2000:23). Segundo José Gregori, o trabalho da CJP consistia em receber denúncias e pressionar os órgãos do governo no sentido de promover a libertação de presos políticos. Cada uma dessas denúncias era investigada fazendo-se uso do aparelho institucional da Igreja Católica. Para responder a essas demandas, constituiu-se em torno das CJP criadas no Brasil uma Rede Nacional de Advogados da Comissão Justiça e Paz, que mobilizava a assessoria de advogados de alto nível, sem ônus para aqueles que eram defendidos das perseguições engendradas pelo regime de exceção.

De fato, o papel da Igreja Católica na organização e na mobilização da sociedade civil na defesa de seus direitos diante do Estado ditatorial no Brasil foi fundamental entre as décadas de 1960 e 1980 . Ao destacar a preeminência da Igreja Católica, nas décadas de 1960 e 1970, na organização de segmentos subalternos da população na defesa de seus direitos sociais garantidos na Constituição, Doimo (1995) sugere:

$[\ldots]$

não podemos nos contentar com o modo sempre ligeiro com que a presença da Igreja é tratada na literatura específica sobre os movimentos sociais, como se fosse um mero"agente

externo", "mediador" ou "articulador social". Mesmo porque ela não foi simplesmente a "boa mãe", que emprestou seu teto e deu generosa proteção em tempos autoritários: sua ação foi persistente e sensivelmente redobrada durante o período de liberação do sistema político, somente declinando gradualmente, junto com a curva do ciclo reivindicativo, a partir da segunda metade da década de 80 .

Do mesmo modo não podemos ficar imaginando que tudo acontece por obra e graça do "trabalho de base", posto que os "grupos de base" decidiram, aqui e acolá, empreender lutas específicas em torno de determinadas carências. A estrutura oficial - e oficiosa - da Igreja esteve sempre presente, ora mais ou menos, legitimando-as com seu apoio material, organizativo e simbólico (Doimo, 1995:149).

Nesse contexto, é interessante observarmos como a própria cosmologia apresentada por algumas igrejas cristãs no período da ditadura no Brasil passou a interpretar a linguagem bíblica como expressão primeira da necessidade de respeito aos direitos humanos. A máxima cristã, de que os homens foram criados à imagem e semelhança de Deus, transformou-se em palavra de ordem na luta em prol dos direitos humanos. Assim, na medida em que todos os homens eram criados à imagem e semelhança de Deus, qualquer tratamento degradante dispensado a eles degeneraria a dimensão divina que cada um dos homens trazia em si. Daí derivava a razão de se lutar contra a tortura ou tratamentos degradantes. ${ }^{8}$

24 Ao mesmo tempo em que a Igreja Católica, por meio das Comissões de Justiça e Paz, defendia os direitos humanos dos perseguidos políticos, as igrejas protestantes também passavam a se ocupar com esta questão. Em 1973, foi lançado pela Coordenadoria Ecumênica de Serviços um livreto com a Declaração Universal dos Direitos Humanos da ONU, com uma tiragem de 2 milhões de exemplares.

A assimilação dos direitos humanos como uma ideologia cristã, associada, por vezes, ao desenvolvimento da teologia da libertação, cuja opção política era o trabalho com os pobres, propiciou o desenvolvimento, ao longo da década de 1970 e 1980, de inúmeros 
centros e/ou comissões de defesa dos direitos humanos, aglutinando profissionais com saberes especializados, como advogados, sociólogos, arquitetos etc. Estima-se que em 1987 havia 104 desses organismos, distribuídos em todas as capitais e até mesmo em localidades menores, como Marzolêndia (GO), Oriximiná (PA), entre outras (cf. Doimo, 1995). Eram justamente esses centros e comissões de defesa dos direitos humanos que constituíam a base da rede que, nos anos 2000, compunha e propiciava a existência da organização não governamental Movimento Nacional de Direitos Humanos (MNDH). Com base em dados do ano 2000, o MNDH reunia 305 entidades de defesa e promoção dos direitos humanos, muitas das quais organicamente relacionadas a entidades confessionais, fossem elas católicas, protestantes ou de outras denominações religiosas.

Constatamos, assim, que a mobilização dos direitos humanos no Brasil se dá, em um primeiro momento, como tática de resistência e oposição ao exercício da violência de Estado na época da ditadura militar. Em um segundo momento, esta mesma categoria é mobilizada para defender os direitos dos presos comuns. Se no período da ditadura a defesa dos direitos humanos significava sobretudo a defesa dos direitos civis e políticos dos indivíduos, o mesmo ocorreu no I PNDH, em consequência do fato de que o grupo político que protagonizou sua elaboração estava antes articulado em redes de ação política em defesa destes mesmos direitos, em instituições como a Comissão Justiça e Paz e, mais tarde, na Comissão Teotônio Vilela e no NEV. Adicionalmente, parece razoável também supor que a ênfase do I PNDH em ações que promovessem o controle do uso da violência por parte do Estado tenha refletido, de alguma forma, a agenda política e científica dos líderes do próprio NEV à época - Paulo Sérgio Pinheiro e Sérgio Adorno - que tem priorizado os estudos sobre segurança pública, direitos humanos e violência (Tsunoda, 2012:39).

No entanto, a ênfase nos direitos civis e políticos, característica do I PNDH, deve-se também a uma razão histórica própria do momento em que o programa foi formulado. De acordo com Adorno (2010:12), tal fenômeno foi decorrência das restrições impostas pela política econômica e de execução orçamentária no primeiro mandato de FHC. Nos termos do autor, esta política operou como um interdito, por vetar a disponibilização de recursos extraorçamentários para reformar e ampliar a política de direitos humanos então em gestação. Na medida em que as prioridades ou as restrições do governo FHC foram superadas, com a chegada de Luiz Inácio Lula da Silva à Presidência da República, houve uma ampliação dos direitos a serem protegidos nos programas nacionais de direitos humanos que sucederam o primeiro (Adorno, 2010).

\section{Direitos Humanos como política de reconhecimento e gestação de um novo projeto de nação}

Como citei acima, o I PNDH consistia de 228 proposições de ações políticas. De modo pioneiro, destas 228 ações, 104 eram destinadas a grupos populacionais específicos, tidos como mais vulneráveis: crianças e adolescentes; mulheres; população negra; sociedades indígenas; estrangeiros, refugiados e migrantes brasileiros; terceira idade e pessoas portadoras de deficiência. As propostas de ações para cada um destes grupos estavam agrupadas no item Proteção do Direito ao Tratamento Igualitário Perante a Lei. Tal formato do programa derivava, em parte, do fato de ele ser produto de uma declaração do sistema especial do direito público internacional de direitos humanos que, como um dispositivo de governança global particular, pode prescrever ações 
voltadas a segmentos populacionais específicos, à diferença dos pactos. ${ }^{9}$ Segundo Piovesan (1997), nos pactos internacionais o indivíduo genérico, universal é o titular dos direitos. Para efeito das análises apresentadas neste artigo, chamo a atenção para as propostas de políticas públicas voltadas para a população negra e para as sociedades indígenas.

No I PNDH havia 22 propostas de ações dirigidas à promoção dos direitos humanos da população negra. Vejamos alguns exemplos:

População Negra

Curto Prazo:

[...]

Estimular a presença de grupos étnicos que compõem a nossa população em propagandas institucionais contratadas pelos órgãos da administração direta e indireta e por empresas estatais do Governo Federal;

Apoiar as ações da iniciativa privada que realizem discriminação positiva;

Estimular as Secretarias de Segurança Pública dos Estados a realizarem cursos de reciclagem e seminários sobre discriminação racial.

Médio Prazo:

Aperfeiçoar as normas de combate à discriminação contra a população negra;

Criar um banco de dados sobre a situação dos direitos civis, políticos, sociais, econômicos e culturais da população negra na sociedade brasileira que oriente políticas afirmativas visando à promoção dessa comunidade;

Promover o mapeamento e tombamento dos sítios e documentos detentores de reminiscências históricas, bem como a proteção das manifestações culturais afrobrasileiras;

Desenvolver ações afirmativas para o acesso dos negros aos cursos profissionalizantes, à universidade e às áreas de tecnologia de ponta;

[...]

Facilitar a discussão e a articulação entre as entidades da comunidade negra e os diferentes setores do Governo, para desenvolver planos de ação e estratégias na valorização da comunidade negra.

Longo Prazo

[...]

Formular políticas compensatórias que promovam social e economicamente a comunidade negra (Brasil, Ministério da Justiça 1998:68-70).

Das 22 propostas de políticas públicas dirigidas especificamente à população negra, pelo menos nove delas tinham diretamente por objetivo promover sua valorização na construção do país. Outras, por sua vez, voltavam-se à proteção das manifestações culturais afro-brasileiras. Propunha-se também a eliminação de estereótipos que fundamentaram parte do racismo brasileiro, sugerindo-se, inclusive, que negros, pardos e mulatos fossem todos considerados parte do contingente de população negra do Brasil. Sugiro que tais ações sejam tomadas como políticas de reconhecimento, nos termos propostos por Taylor (1994), ou seja, como um tipo de política que se define pela afirmação e a extensão da percepção de dignidade e mérito a identidades coletivas minoritárias inseridas no interior de comunidades políticas englobantes. Para este autor, o reconhecimento constitui a base para o acesso de determinados segmentos sociais a direitos diferenciados por grupo, pois estes últimos só serão aceitos se as identidades cultivadas pelos grupos minoritários forem apreendidas como legítimas pela cultura societária abrangente (Kymlicka, 1995).

31 Ao propor políticas de reconhecimento tal como apresentadas acima, o governo assumia que o status simbólico e a condição social da população negra no país eram injustos. Também está implícito na retórica do governo o reconhecimento de que o 
Brasil não era o país da democracia racial (Freire, 1995). Ao contrário, ao propor ações que coibiam práticas de discriminação, o Estado reconhecia que elas existiam. Mas o I PNDH foi além. Entre as ações previstas para a população negra, o Estado propôs, pela primeira vez, políticas de ação afirmativa, denominadas ora discriminação positiva, ora políticas compensatórias. ${ }^{10}$

O reconhecimento do racismo no Brasil e a consequente crítica ao mito da democracia racial continuaram a se fazer presentes em outros atos de Estado no governo Fernando Henrique Cardoso. Em junho de 1996, por exemplo, no Seminário Multiculturalismo e Racismo, promovido pelo Ministério da Justiça, o presidente da República afirmou: ${ }^{11}$

Nós, brasileiros, pertencemos a uma nação cheia de contrastes e de desigualdades de todo o tipo, mas também de diferenças - que não só desigualdades - de raça, de cor, de cultura. [...]

Houve época, no Brasil, em que muitos se contentavam em dizer que, por haver essa diversidade, o país não abrigava preconceitos. Isso, contudo, não é verdade.

[...]

Ao contrário, existem muitos aspectos de intolerância, quase sempre disfarçada pela tradição paternalista de nosso velho patriarcalismo, e sempre um pouco edulcoradas, adocicadas, porque raramente manifestamos nossas distâncias e nossas reservas de forma áspera. Frequentemente, essa intolerância é expressa com alguma tranquilidade, o que representa, de certa maneira, uma atitude de hipocrisia.

[...]

Nós, no Brasil, de fato convivemos com a discriminação e convivemos com o preconceito, mas "as aves que aqui gorjeiam, não gorjeiam como lá", o que significa que a discriminação e o preconceito que aqui temos não são iguais aos de outras formações culturais (Cardoso, 1997: 13-6).

Tendo por base o conteúdo do discurso acima e a proposição de políticas públicas diferenciadas por grupo no I PNDH, arrisco-me a sugerir que a política de direitos humanos no Brasil criou condições para a afirmação das diferenças, o reconhecimento das desigualdades entre diversos estratos populacionais e o questionamento da miscigenação como ideal cultural e político na formação e na reprodução da nação. Isto porque, além de propor políticas de ação afirmativa, o I PNDH sugeria também ações em prol do destaque da presença negra no espaço público nacional e do que eram consideradas suas expressões culturais características. Estávamos, pois, diante de ações que tinham como fim superar desigualdades, mas não certas diferenças culturais em prol da construção de um híbrido nacional formado a partir de substratos de diferentes origens. Ao contrário, tratava-se de ações que promoviam as diferenças a fim de revigorá-las e permitir uma coexistência mais justa entre elas. Tal tendência se fazia também presente nas propostas de ações voltadas às sociedades indígenas no I PNDH. Vejamos alguns exemplos.

Sociedades Indígenas

Curto Prazo:

Formular e implementar políticas de proteção e promoção dos direitos das sociedades indígenas, em substituição a políticas assimilacionistas e assistencialistas;

Assegurar a participação das sociedades indígenas e de suas organizações na formulação e implementação de políticas de proteção e promoção de seus direitos; Assegurar o direito das sociedades indígenas às terras que elas tradicionalmente ocupam;

$[\ldots]$ 
Assegurar às sociedades indígenas uma educação escolar diferenciada, respeitando o seu universo sociocultural;

Promover a divulgação de informação sobre os indígenas e os seus direitos, principalmente nos meios de comunicação e nas escolas, como forma de eliminar a desinformação (uma das causas da discriminação e da violência contra os indígenas e suas culturas), (Brasil/Ministério da Justiça, 1998). constitucional de 1988, que reconhece a condição de índio como um estado permanente e não provisório, rompendo, portanto, com expectativas assimilacionistas. Tal pressuposto informa a maioria das demais propostas voltadas às populações indígenas no programa, uma vez que a não assimilação tem como condição a manutenção e a sobrevivência do referencial material, ecológico e cultural que permite a essas sociedades suas existências físicas e morais. Daí o incentivo à criação de sistemas educacional e de saúde diferenciados, os quais respeitem o universo sociocultural dessas populações.

É interessante destacar também a proposta do programa de divulgar informações sobre os indígenas e seus direitos enquanto estratégia de eliminar a desinformação, percebida

te documento como uma das causas da discriminação e da violência contra os indígenas e suas culturas. Interpreto tal proposta de ação como um meio de promover o correto reconhecimento das populações indígenas, o qual, por sua vez, teria efeitos importantes na própria manutenção e no fortalecimento de tais coletividades, dado o caráter relacional da produção das identidades.

A valorização da diferença e a negação da assimilação no I PNDH tinham, porém, limitações. Primeiramente, elas pareciam alicerçadas em noções sedimentadas ao longo do tempo a respeito do modo como as populações indígenas e as populações negras participavam da coletividade nacional. Nota-se, por exemplo, que o I PNDH referia-se às populações indígenas, no plural, como localizadas sempre em terras indígenas. Não havia indicação de ações para índios vivendo em territórios urbanos. Por sua vez, as ações voltadas à população negra, referida no singular, não faziam qualquer citação direta a comunidades remanescentes de quilombos e aos seus territórios correspondentes.

Secundariamente, o reconhecimento, a promoção e a proteção da diferença no I PNDH foram estendidos a grupos cujas identidades eram consensualmente reconhecidas como legítimas entre as forças políticas que, ao longo do tempo, alçaram os direitos humanos como um mobilizador político no espaço público nacional. A este respeito, é digno de nota que o I PNDH não previa ações direcionadas exclusivamente aos homossexuais, a despeito das demandas apresentadas por entidades que trabalhavam em defesa dos direitos deste grupo. Exploro, na seção seguinte, a controvérsia que se desenvolveu entre o NEV e a Associação Brasileira de Gays, Lésbicas e Travestis (ABGLT) no processo de formulação do I PNDH. Argumento que a controvérsia e o que dela resultou revelam, por um lado, os efeitos de poder de tramas institucionais confessionais sobre o Estado e, de outro lado, alguns desafios que se impõem à universalização e ao reconhecimento de direitos nos espaços públicos nacionais, nomeadamente no que diz respeito à articulação entre noções de direito e identidade. 


\section{De bons e maus oprimidos}

Como relatei anteriormente, a elaboração do I PNDH se deu mediante um processo de consulta às instituições da sociedade civil vocacionadas à defesa dos direitos humanos. Para tanto, o NEV convocou tais instituições a apresentarem informações sobre violação de direitos humanos e sugestões de ações do Estado para coibi-las. Tais informações e sugestões foram enviadas por correspondência ou apresentadas em seminários regionais. A Associação Brasileira de Gays, Lésbicas e Travestis encaminhou ao NEV/USP sugestões de políticas públicas direcionadas aos homossexuais. Em correspondência remetida ao NEV-USP em 04/11/1995, como resposta à circular expedida pela mesma instituição em 23/10/1995, solicitando informações sobre a violação dos direitos humanos dos homossexuais no Brasil, Luiz Mott, como secretário de Direitos Humanos da ABGLT apresentou o seguinte retrato e sugestões:

Segundo estimativa baseada no Relatório Kinsey (1948), os homossexuais devem representar no mínimo $10 \%$ da população brasileira, estando presentes em todos os segmentos sociais, raças, idades, e etnias. De acordo com pesquisa do IBOPE, DataFolha e Agência Estado, gays e lésbicassão as principais vítimas do preconceito e discriminação no Brasil [...].

Assim sendo, a Associação Brasileira de Gays, Lésbicas e Travestis (ABGLT), através de sua Secretaria de Direitos Humanos, sugere cinco medidas para estancar a violação dos direitos humanos dos homossexuais no Brasil:

1. Averiguação e punição exemplar dos crimes de discriminação e assassinato de homossexuais;

2. Aprovação da emenda incluindo na Constituição Federal a proibição de discriminação por orientação sexual, assim como nas leis orgânicas Municipais e Constituições Estaduais;

3. Inclusão em todos os documentos oficiais e cursos sobre Direitos Humanos a defesa dos homossexuais ao lado das demais minorias discriminadas;

4. Inclusão da variável "orientação sexual" nas estatísticas de crimes de ódio;

5. Obrigatoriedade de cursos de orientação sexual nas escolas em todos os níveis, ensinando a verdade científica sobre a homossexualidade.

Enviada tal correspondência ao NEV, entidades representativas da defesa dos direitos dos homossexuais vieram a ter contato novamente com a equipe responsável pela elaboração do I PNDH somente na I Conferência Nacional de Direitos Humanos, realizada em Brasília nos dias 26 e 27 de abril de 1996. O Grupo Estruturação, sediado em Brasília, participou do evento e constatou a ausência de ações voltadas exclusivamente à promoção dos direitos humanos dos homossexuais, a despeito das sugestões apresentadas. Diante de tal fato, o grupo encaminhou à equipe responsável pela elaboração do programa propostas de ações para proteção dos direitos humanos dos homossexuais, a serem incluídas em um subitem direcionado especificamente a esta coletividade, na seção "Proteção do direito ao tratamento igualitário perante a lei". Eis alguns exemplos das ações propostas para inclusão no I PNDH pelo grupo Estruturação:

Curto Prazo:

Implementar o programa nacional de prevenção à violência contra os homossexuais;

Incentivar programas de orientação familiar com o objetivo de capacitar as famílias e, principalmente pais e mães, no esclarecimento de questões ligadas à homossexualidade e incentivar o apoio a crianças e adolescentes prevenindo atitudes hostis e violentas;

$[\ldots]$ 
Proteger os homossexuais contra agressões e divulgação de ideias discriminatórias, seja pelas igrejas, imprensa ou qualquer outros meios de divulgação de informação ou ideologia;

[...]

Apoiar a regulamentação da união civil entre pessoas do mesmo sexo, já tramitando na Câmara Federal, através do Projeto de Lei no. 1151/95, da deputada Marta Suplicy.

Médio Prazo

[...]

Promover o reconhecimento, o apoio e a defesa do homossexual, dentro dos diversos grupos sociais (anexo da correspondência enviada pelo Grupo Estruturação a Luiz Mott, secretário de Direitos Humanos da ABGLT, em 02/05/1996).

Diagnosticada a possibilidade de os homossexuais não serem incluídos no PNDH como uma categoria para a qual se dirigiriam políticas públicas particulares, iniciou-se um processo de articulação entre as entidades que representavam e defendiam os interesses deste segmento social. O manifesto de protesto, intitulado "Plano de Direitos Humanos discrimina homossexuais", revela alguns dos termos em torno dos quais se desenvolveria uma controvérsia entre o NEV/USP e entidades representativas desse grupo, na qual, como poderemos observar, a questão do reconhecimento da legitimidade da identidade homossexual teve lugar central. Assinado por Luiz Mott e Vânia Dignidade, afirma este documento:

Luiz Mott [...] aceitou o convite para estar no Palácio do Planalto na próxima segunda-feira, acatou a exigência de usar terno e gravata, mas declarou não abrir mão de seu direito humano de protestar contra o absurdo deste Plano que, ao omitir os homossexuais, legitima nova categoria de discriminação: de um lado, os bons oprimidos, os meninos de rua, negros, índios, cujos direitos o governo e a Igreja vão defender, do outro lado, os maus oprimidos, os gays, lésbicas e travestis, que continuarão sendo massacrados, enquanto esperam a sua Lei Áurea de libertação.

Caso se confirme a omissão dos homossexuais do Plano, grupos gays do Paraná, Rio de Janeiro, Bahia e Brasília vão queimar em praça pública o plano de Direitos Humanos após o seu lançamento... (documento s/d).

41 Como podemos observar no trecho acima transcrito, bem como nas propostas apresentadas pelos homossexuais na I Conferência Nacional de Direitos Humanos, uma das demandas principais deste grupo era que sua identidade fosse reconhecida como legítima tanto quanto o era a de negros, índios, crianças, entre outros. A oposição exposta no manifesto entre bons oprimidos versus maus oprimidos é reveladora da articulação entre identidade e direitos que antecipei acima. Sugere-se que o I PNDH e a Igreja protegem os bons oprimidos e o fazem justamente porque eles são considerados bons, tendo suas identidades aceitas e protegidas por tais instituições. Por oposição, o I PNDH deixaria a descoberto os maus oprimidos por cultivarem a particularidade de sua identidade, o homossexualismo, que não é aceito como legítimo e positivo pelo Estado e pela Igreja.

Não obstante as sugestões dos homossexuais terem sido apresentadas em tempo hábil para que pudessem ser incorporadas ao PNDH, elas não o foram. ${ }^{12} \mathrm{O}$ I PNDH não apresentou aos homossexuais propostas de políticas públicas diferenciadas, o que desencadeou, a partir de então, uma série de manifestações de protesto em relação ao programa. ${ }^{13}$ Dentre elas, destaca-se a seguinte correspondência enviada por Luiz Mott ao NEV:

[...] A omissão de propostas específicas de proteção aos homossexuais explica-se não só pela dificuldade dos governos em lidar com a minoria mais discriminada no país 
(conforme atestam pesquisas da Data-Folha, Agência Estado, Revista Veja), como pelo próprio preconceito ainda enraizado não apenas entre os donos do poder.

[...]

[...] A argumentação do coordenador científico do NEV-USP [Paulo S. Pinheiro] de que das cinco propostas enviadas pelo GGB [Grupo Gay da Bahia], três foram contempladas, tenta mascarar a forma discriminatória e injusta como os homossexuais foram tratados pelo NEV-USP e pelo PNDH, na medida em que, seguindo-se esta mesma linha de raciocínio, por que privilegiar a população negra com oito medidas a curto prazo, 12 a médio prazo e duas a longo prazo - num total de 22 propostas específicas - se tal segmento também já se beneficia das mesmas propostas "que dizem respeito diretamente à proteção dos direitos" de todos os demais grupos discriminados?!

O que justifica a proposta da inclusão do "quesito cor em todos e quaisquer sistemas de informação e registro sobre a população" e a exclusão de nossa proposta de "inclusão da variável orientação sexual nas estatísticas e crimes de ódio"? Preconceito e tratamento discriminatório contra as minorias sexuais! Por que privilegiar "ações afirmativas para o acesso dos negros aos cursos profissionalizantes, às universidades e às áreas de tecnologia de ponta" e a rejeição de nossa proposta de "obrigatoriedade de cursos de orientação sexual nas escolas em todos os níveis, ensinando a verdade científica sobre a homossexualidade?" Homofobia. O que, além de preconceito e discriminação justifica a proposta "Adoção do princípio de criminalização da prática do racismo, nos Códigos Penal e de Processo Penal?", e a rejeição de nossas propostas de "averiguação e punição exemplar dos crimes de discriminação e assassinato de homossexuais"?! [...]

Se até os estrangeiros - um dos grupos mais benquistos pelos brasileiros em geral sensibilizam o NEV-USP, que propõe "adotar medidas para impedir e punir a violência e a discriminação contra estrangeiros no Brasil e brasileiros no exterior" (sic), somente a homofobia ou inaceitáveis pressões de setores mais retrógrados de nossa sociedade explicariam a exclusão de nosso pleito de "averiguação e punição exemplar dos crimes e discriminação e assassinatos de homossexuais".

Assim sendo, ratificamos nosso protesto contra a odiosa discriminação de que foram e continuam sendo vítimas os homossexuais por parte dos responsáveis do NEV-USP (Carta enviada por Luiz Mott para Paulo Sérgio Pinheiro em 29/06/1996).

Verificamos, por meio da narrativa acima, que a percepção de exclusão dos homossexuais se dá como efeito da comparação com o reconhecimento e a proteção de outras coletividades vulneráveis feitos pelo I PNDH, algumas das quais consideradas pela ABGLT menos expostas a violações de direitos humanos que aqueles que se apresentam como homossexuais. Não bastava, para esta instituição, que parte de suas demandas estivesse diluída em outros trechos do PNDH, como, por exemplo, na introdução deste documento, no qual se reconhecia o direito de "ser, pensar, crer, de manifestar-se ou de amar sem tornar-se alvo de humilhações, discriminação ou perseguição". O mesmo se dando no primeiro item da seção "Proteção ao direito igualitário perante a lei", no qual se propunha elaboração de legislação proibindo todo tipo de discriminação, com base em raça, etnia, sexo, idade, credo religioso, convicção política ou orientação sexual (Brasil/Ministério da Justiça 1998:46). ${ }^{14}$

O foco das demandas da ABGLT era pela inclusão dos homossexuais no I PNDH como alvo de políticas específicas de proteção e reconhecimento, do que decorreria, indiretamente, reconhecimento da identidade cultivada por tal coletividade. No limite, a ABGLT demandou do Estado uma política de correto reconhecimento (Taylor, 1994) dos homossexuais que permitisse, em decorrência disso, a formulação de políticas particulares para a sua proteção. A negação de tal demanda parece ter gerado uma percepção de desconsideração, entendida aqui como um insulto moral decorrente da 
ausência de demonstração de respeito e deferência à identidade cultivada por um interlocutor (Cardoso de Oliveira, 2007). De fato, a ausência de referência direta e explícita aos homossexuais impediu a elaboração de ações voltadas exclusivamente a eles.

Várias podem ter sido as razões que resultaram nessa configuração dos fatos. Dos dados produzidos ao longo da pesquisa, duas variáveis importantes se destacam para dar sentido a tal fenômeno. A primeira diz respeito ao poder de influência da Igreja Católica e de outras entidades cristãs, no passado, na articulação de políticas em prol dos direitos humanos no Brasil, cujos legados se fazem sentir contemporaneamente. Em um segundo plano, o silenciamento da CPNDH em relação às demandas dos homossexuais pode ser resultado de um cálculo político que antevia maiores dificuldades no trabalho de advocacy em prol do I PNDH junto a órgãos do Estado, em diferentes níveis administrativos, se este contemplasse políticas de proteção aos homossexuais. Vejamos.

46 Na primeira seção deste artigo demonstrei que a gênese da mobilização em prol dos direitos humanos no Brasil foi liderada pela Comissão Pontifícia de Justiça e Paz, entidade ligada ao Vaticano e à Igreja Católica no Brasil. Destaquei também a sua importância na criação de instituições da sociedade civil no Brasil empenhadas na defesa dos direitos humanos, as quais, no ano 2000 somavam mais de 300 entidades, sob a articulação do Movimento Nacional de Direitos Humanos que, à época, era inclusive dirigido pelo reverendo Romeu Olmar Klich. Diante destes fatos, parece-me razoável supor que a Igreja Católica e outras entidades confessionais acumularam capital político que lhes permitiam exercer influência sobre as políticas de Estado neste campo, de modo a não verem contrariados seus princípios dogmáticos, dentre os quais se destacava, naquele período, a negação da homossexualidade como uma escolha legítima. Ao mesmo tempo, parece-me verossímil pressupor também que vários compromissos foram sendo construídos, de maneira mais ou menos explícita, entre aqueles que protagonizaram a institucionalização da política de Estado de direitos humanos com a Igreja Católica ao longo de suas respectivas trajetórias de militância em prol dos direitos humanos nas dependências desta mesma Igreja.

47 Tal hipótese ganha força se levarmos em consideração a conduta do então deputado Hélio Bicudo, presidente da Comissão de Direitos Humanos em 1996, uma das principais entidades responsáveis pela I Conferência Nacional de Direitos Humanos, em relação ao projeto de lei (PL) 1.151/95, de autoria de Marta Suplicy. Este projeto de lei regulamentava a união civil entre pessoas do mesmo sexo, propondo, em consequência, a institucionalização positiva da orientação homossexual. Quando da discussão do projeto de lei na Comissão de Direitos Humanos, Hélio Bicudo mostrou-se veementemente contra ele, afirmando que tinha conteúdo "hedonista, incompatível com a finalidade última da espécie humana, que não pode compadecer com considerações que qualificam o homem [...] vivendo preponderantemente para o prazer. [...]" (Folha de São Paulo, 30/06/1996). Neste ponto, faz-se necessário lembrar que Hélio Bicudo foi um dos fundadores da Comissão Teotônio Vilela, tendo desenvolvido parte importante de sua carreira política em torno da defesa dos direitos humanos. Ainda sobre o PL supracitado, o deputado comentou:

O projeto que trata da chamada união civil estabelece a possibilidade de existência de uma família paralela - inteiramente discrepante dos grupos familiares contemplados pela Constituição Federal, o que seria suficiente para inviabilizá-lo de plano, apontando-lhe a mesma sorte das propostas de esterilização e aborto, 
atentando estas contra claros direitos e garantias constitucionais - para fins exclusivamente patrimoniais (Folha de São Paulo, 30/06/1996).

Tendo em conta os fenômenos identificados acima, observa-se que, no campo de disputa política existente em torno dos direitos humanos nos primórdios de sua institucionalização enquanto política de Estado, o poder das igrejas cristãs manifesta-se sobretudo por meio de seus efeitos (Foucault, 2000). As possibilidades de instituições cristãs influenciarem a conduta e as decisões do Estado tornam-se evidentes quando mapeamos a rede através da qual o seu poder circula, os sujeitos por meio dos quais elas atuam, bem como os fenômenos morais que elas agenciam.

Ao entrevistar servidores públicos de alto escalão responsáveis pela execução do I PNDH na Secretaria de Estado de Direitos Humanos, em 1999, pude também verificar que a lógica que orientou a inclusão de coletividades como alvos de ações especiais no programa

não foi somente o reconhecimento de que estas seriam as mais vulneráveis a violações de seus direitos. Suas identidades tinham que ser consensualmente reconhecidas como

legítimas pelas diferentes instituições responsáveis por ações em prol dos direitos humanos em diferentes níveis do Estado. Vejamos como alguns de meus interlocutores davam sentido a tais fatos,

Pra gente é um tema novo [o homossexualismo], porque a gente tá engatinhando ainda, eu acho. É um trabalho muito difícil, eu acho que de todos os que a gente trabalha é o mais difícil, aquele que o pessoal tem mais resistência. Não é uma coisa fácil você chegar e convencer os seus parceiros dos direitos dos homossexuais, não é uma coisa que a gente pode falar abertamente na esplanada, pelo menos por enquanto. Mas temos conseguido alguma coisa [...] É mais difícil porque a gente trabalha com o convencimento das pessoas, inclusive pra gente poder executar. Então é onde a gente encontra mais resistência, não é uma coisa passiva... principalmente porque não existe quase legislação em relação a isso e existe muito preconceito. [...] Existe uma grande dificuldade, que é a pouca força institucional dos homossexuais, porque eles não se reconhecem muitas vezes como homossexuais, é muito difícil que a pessoa se reconheça publicamente como homossexual. [...] Então, de todos os grupos é o que a gente mais tem dificuldade por conta disso; e também porque de todos os assuntos de pauta dos Direitos Humanos é o mais novo (Patrícia Audi, gerente do

Qualquer coisa que você faça em nível de governo federal, você trabalha com vários parceiros. Então, pra você fazer parceria com alguém, o outro também precisa concordar com você. Se eu vou fazer uma parceria com a Secretaria de Segurança da Bahia, e aí ele fala que com negócio de gay a gente não mexe, como é que você vai fazer? Vou forçar o cara, ele não vai querer fazer (Ivair A. dos Santos, diretor do Departamento de Direitos Humanos).

Com base em tais informações, sugiro que um dos critérios que nortearam a inclusão ou a exclusão de determinadas categorias de identidade no I PNDH como merecedoras de políticas públicas específicas foi, também, o grau de legitimidade, de visibilidade moral dessas identidades junto a diferentes setores da sociedade. Assim, a exclusão dos homossexuais do I PNDH como categoria específica na seção "Proteção do direito ao tratamento igualitário perante a lei" pode ser interpretada como resultado de uma tática política em relação a alguns setores mais conservadores da sociedade civil, como a Igreja Católica, por exemplo, a fim de garantir ao programa maior apoio e sustentação. Aqui, a relação entre direitos e identidade social revela uma dimensão importante do processo de construção da nação no Brasil, como um projeto de coletividade política formada por partes que se pensam como iguais. Observa-se que a 
valorização/legitimação de certas identidades se constitui num condicionante significativo para que indivíduos com posições de sujeito particulares tenham seus direitos mais elementares reconhecidos e assegurados pelo Estado.

\section{Considerações finais}

51 Ao longo deste artigo procurei objetivar parte das origens das políticas de Estado de direitos humanos no Brasil e seus potenciais quando de sua institucionalização em 1996. Argumento que sua genealogia inscreve-se, primeiramente, na resistência e na oposição ao regime militar nas décadas de 1970 e 1980, articuladas sob a proteção institucional da Igreja Católica, sob a Comissão Pontifícia de Justiça e Paz em São Paulo. Em um segundo momento, muitos dos atores sociais envolvidos em tais práticas vieram a rearticular suas ações políticas em defesa dos direitos humanos de presos comuns ou de pessoas reclusas em instituições fechadas, no âmbito da Comissão Teotônio Vilela, a qual, por sua vez, fomentou a criação do Núcleo de Estudos da Violência da Universidade de São Paulo. Coube ao NEV, não por acaso, formular o projeto do I Programa Nacional de Direitos Humanos.

Argumento, assim, que a gênese da política de Estado de direitos humanos no Brasil se deve em grande parte às ações engendradas por estas três instituições e pelas redes de pessoas que as constituíam e atravessavam, algumas das quais, nos governos FHC, tendo ocupado importantes posições de Estado. Interpreto a ênfase dada aos direitos civis e políticos no âmbito do I PNDH como um legado, em parte, do ativismo destes atores em torno desta mesma agenda no período da ditadura. Ademais, destaco a importância da Igreja Católica e outras denominações religiosas na organização da sociedade civil em prol dos direitos humanos, a partir da década de 1970, cujos efeitos se fizeram sentir quando da formulação do próprio I PNDH.

Mediante a análise das ações voltadas à população negra e às populações indígenas na seção "Proteção do Direito a Tratamento Igualitário perante a Lei" do I PNDH, indico o caráter pioneiro deste programa no que diz respeito ao projeto de constituição nacional nele inscrito. Suas propostas de ação visavam ao reconhecimento e àmanutenção das diferenças culturais da população negra e das populações indígenas na coletividade nacional, colocando assim em suspensão a miscigenação ou a hibridização cultural como ideal social e político. Ao longo do texto, demonstro que tais proposições, enquanto atos de Estado, não se faziam de modo isolado e exclusivo no âmbito do I PNDH. Pelo contrário, fizeram-se presentes em vários outros discursos do então presidente Fernando Henrique Cardoso no período.

Na terceira seção do artigo exploro a controvérsia que se desenvolveu entre entidades defensoras de interesses de coletivos homossexuais e o NEV no processo de formulação do I PNDH. A análise da controvérsia demonstra que o programa foi tomado pela sociedade civil como espaço para políticas de correto reconhecimento por parte do Estado. Assim, a exclusão dos homossexuais do I PNDH foi lida pela ABGLT como um ato de desconsideração. Ademais, argumento que tal exclusão é exemplar de alguns dos condicionantes que se impõem às práticas de extensão efetiva de direitos no Brasil, para além de suas definições normativas. Tais práticas parecem sempre exigir o reconhecimento anterior das identidades às quais os direitos se referem. Ao mesmo tempo, o não atendimento das demandas da ABGLT pelo NEV e pelo próprio governo nesse período parece ser resultado do poder da Igreja Católica e de outras entidades 
confessionais no campo político dos direitos humanos, o qual remete à própria emergência dos direitos humanos como mobilizador político no Brasil, na época da ditadura militar.

Por fim, arrisco-me a concluir este artigo com a proposição de uma hipótese, da qual somente pesquisas posteriores poderão dizer se é ou não plausível. Mais do que a proposição de uma hipótese, talvez o que esteja em pauta é mesmo a sugestão de uma agenda de pesquisa. Entre as razões que me fizeram retomar o material de pesquisa que produzi há 15 anos, aproximadamente, para a escrita desde artigo, destaca-se a convicção de que o I PNDH e os vários atos de Estado que foram realizados no primeiro mandato de FHC tiveram papel pioneiro no reconhecimento da desigualdade racial no Brasil contemporâneo. E já que estamos falando de genealogias, penso que uma das genealogias para as políticas de ação afirmativa no Brasil contemporâneo certamente se inscreve nos atos de Estado aqui recuperados.

Mas, obviamente, estes atos de Estado não são produto de geração espontânea. Eles foram provocados, foram produzidos pela ação política de outros agentes, dos quais se destacam as várias frentes do movimento negro no Brasil e intelectuais de diferentes perfis, inclusive Fernando Henrique Cardoso que, na década de 1950, participou do famoso Projeto Unesco. ${ }^{15}$ Ocorre-me pensar então nos processos e nos fenômenos que permitiram a tais atores imaginar e construir a pauta política de reconhecimento e proteção das manifestações culturais afro-brasileiras e de políticas de ação afirmativa. $\mathrm{Na}$ gênese desta pauta política, não estariam fenômenos de ordem transnacional relacionados com a difusão de modelos e práticas de governo de origem anglo-saxã, estruturadas por um paradigma de organização do espaço público e da ação política etnicizados? Assim como a I PNDH nasceu parcialmente como resposta a um dispositivo de governança global, a Declaração de Direitos Humanos de Viena, parece-me relevante aventar em que medida as políticas de ação afirmativa se apresentam como produto de uma história global de relações entre elites transnacionais e seus modelos e práticas de governo, relações quetêm permitido a própria articulação e a gestação do sistema mundial (Wallerstein, 1974; Ribeiro, 2013) tal como o conhecemos.

\section{BIBLIOGRAFIA}

ADORNO, Sérgio. 2010. “História e Desventura: o 3 Programa Nacional de Direitos Humanos". Novos Estudos, 86:5-20.

ARQUIDIOCESE DE SÃO PAULO. 1985. Brasil: nunca mais. Petrópolis: Editora Vozes.

BERNARDINO, Joase. 2002. “Ação Afirmativa e a Rediscussão do Mito da Democracia Racial no Brasil”. Estudos Afro-Asiáticos, 24 (2):247-273.

BRASIL/MINISTÉRIO DA JUSTIÇA. 1998. Programa Nacional de Direitos Humanos. Brasília. BRASIL/ PRESIDÊNCIA. 1995. Direitos Humanos: novo nome da liberdade e da democracia. Brasília: Presidência da República. Secretaria de Comunicação Social, Ministério da Justiça, Ministério das Relações Exteriores. 
1998. Construindo a democracia racial. Brasília: Presidência da República.

CALDEIRA, Teresa P. R. 1984. A Política dos outros. São Paulo: Editora Brasiliense.

1992. City of Walls: Crime, Segregation and Citizenship in São Paulo. Tese de Doutorado, Universidade da Califórnia, EUA.

CARDOSO, Fernando Henrique. 1997. Pronunciamento do Presidente da República na abertura do Seminário Multiculturalismo e Racismo. In: Jessé Souza, et alli (org.). Multiculturalismo e racismo: uma comparação Brasil-Estados Unidos. Brasília: Paralelo 15.

CARDOSO DE OLIVEIRA, L. R. 2007. “Honneur, dignité et réciprocité”. In: A. Caillé (ed.). La quête de reconnaissance: Nouveau phénomène social total. Paris: Editions: La Decouverte. p. 89-103.

DOIMO, Ana Maria. 1995. A vez e a voz do popular: Movimentos Sociais e participação política no Brasil pós-70. Rio de Janeiro: Relume Dumará.

ELIAS, Norbert. 1999. Os Alemães: a luta pelo poder e a evolução do habitus nos séculos XIX e XX. Rio de Janeiro: Jorge Zahar Ed.

. 2006. "Processos de formação de Estados e construção de nações". In: Frederico Neiburg \& Leopoldo Waizbort (orgs.). Norbert Elias. Escritos e Ensaios 1. Estado, processo e opinião pública. Rio de Janeiro: Jorge Zahar Ed.

FREIRE, Gilberto. 1995. Casa-grande e Sensala. Rio de Janeiro: Record.

FOUCAULT, Michel. 2000. Microfísica do poder. Rio de Janeiro: Edições Graal.

KYMLICKA, Will. 1995. Multicultural Citizenship: a liberal theory of Minory Rights. Oxford: Claredon Press.

MARSHALL, T. H. 1956. “Cidadania e Classe Social”. In: . Cidadania, Classe e Status. Rio de Janeiro, Zahar Ed.

MAIO, Marcos Chor. 1999. "O Projeto Unesco e a agenda das ciências sociais no Brasil dos anos 40 e 50”. Revista Brasileira de Ciências Sociais, 14 (41):141-158. Disponível em: http://www.scielo.br/ scielo.php?pid=S0102-69091999000300009\&script=sci_arttext. Acesso em: 08/05/2014.

PINHEIRO, Paulo Sérgio. 1997. "Violência, crime e sistemas policiais em países de novas democracias". Tempo Social - Revista de Sociologia da USP, 9 (1):43-52.

PIOVESAN, Flávia. 1997. Direitos Humanos e o Direito Constitucional Internacional. São Paulo: Max Limonad.

RIBEIRO, Gustavo. 2013. "Global Flows of Development Models”. Anthropological Forum, 23 (2): 121-141.

RIBEIRO, Marcos Abraão Fernandes. 2011. "As relações raciais na obra de Fernando Henrique Cardoso e a dimensão moral do racismo". Anais do Seminário Nacional da Pós-Graduação em Ciências Sociais - UFES. Disponível em: http://periodicos.ufes.br/ SNPGCS/article/viewFile/1487/1075 . Acesso em: 08/05/2014.

SILVA, Kelly C. 2000. O novo nome da democracia. A retórica sobre direitos humanos no governo FHC. Dissertação de Mestrado, Universidade de Brasília.

TAYLOR, Charles. 1994. "The Politics of recognition”. In: Amy Gutmann. Multiculturalism: examining the politics of recognition. Princenton: Princenton University Press.

TSUNODA, Fábio Silva. 2012. Comissão Teotônio Vilela (CTV). Direitos humanos e vocação militante. Dissertação de Mestrado, Universidade de São Paulo. 
WESTON, Burns, H. 1985. “Human Rights”. Encyclopedia Britannica. 15th ed., 20:713-721.

WALLERSTEIN, Immanuel. 1974. The modern world system. New York: Academic Press.

WOLF, Eric. 2003. “Parentesco, amizade e relações patrono-cliente em sociedades complexas”. In: Bela Feldman-Bianco \& Gustavo Lins Brasília Ribeiro (orgs.) Antropologia e Poder. Contribuições de Eric R. Wolf. Brasília: Editora Universidade de Brasília; São Paulo: Imprensa Oficial do Estado de São Paulo; Campinas: Editora Unicamp.

. 2011. “Aspects of Group relations in a Complex Society: Mexico". In: Pathways of Power. Building an Anthropology of the Modern World. Berkeley: University of California Press.

\section{NOTAS}

1. No espaço deste artigo, trabalho com as acepções propostas por Marshall (1956) para as noções de direitos civis, políticos e sociais. $\mathrm{O}$ autor define estes três tipos de direito nos seguintes termos: os direitos civis são aqueles que garantem o exercício da liberdade individual - pensamento, fé, de ir e vir etc.; os direitos políticos são aqueles que resguardam o direito do indivíduo de participar do poder político, quer como um membro investido de autoridade política, quer como um eleitor dos membros de tal organismo; e, por fim, os direitos sociais são aqueles que garantem o gozo de um mínimo de bem-estar.

2. Em relação a esta questão, Wolf (1974:2) afirma: “[...] a estrutura de poder político e econômico existe justaposição, ou entremeada, a vários outros tipos de estruturas informais que lhe são intersticiais, suplementares, paralelas [...]". Em outra obra, o mesmo autor (2001) nos adverte que um estudo mais eficiente do funcionamento das sociedades complexas só pode ser alcançado se focalizarmos nossa atenção nas relações desenvolvidas entre os diferentes grupos que as compõem e nas formas como eles interagem entre si em diferentes níveis da sociedade. Para Wolf, estas sociedades se constituem a partir de redes de relações entre grupos que conectam localidades e instituições através de grupos de pessoas. Elias (2006:156), por sua vez, declara: "Por que pôr as ações no centro de uma teoria social da sociedade, e não as pessoas que agem? As sociedades são redes de seres humanos, não um emaranhado de ações incorpóreas".

3. Os dados analisados no âmbito deste artigo deram origem, primeiramente, à minha dissertação de mestrado, intitulada 0 novo nome da democracia: a retórica sobre os direitos humanos no governo Fernando Henrique Cardoso. Esta dissertação foi aprovada pelo Programa de Pós-Graduação em Antropologia Social da Universidade de Brasília em abril de 2000, e orientada por Luís Roberto Cardoso de Oliveira.

4. A totalidade do I PNDH encontra-se disponível no seguinte endereço eletrônico: http:// www.dhnet.org.br/dados/pp/pndh/textointegral.html. Acesso em: 29/04/2014.

5. Segundo a classificação de Karel Vasak, inspirada nos ideais de liberdade, igualdade e fraternidade colocados pela Revolução Francesa, os direitos humanos, tal como definidos na Declaração Universal de Direitos Humanos, incluem três gerações de direitos: a primeira delas faz referência aos direitos que garantem a liberdade, nos quais estão contidos os direitos civis e políticos prescritos na declaração universal nos artigos de nº 1 a 21. Neles estão garantidos, por exemplo, a liberdade de pensamento, crença e religião, o direito à privacidade, à proteção contra a discriminação, o direito de participação no governo etc. A segunda geração de direitos protege os indivíduos contra os abusos do capitalismo, garantindo-lhes um grau mínimo de equidade. Essas garantias prescrevem, entre outras coisas, o direito ao trabalho, à seguridade social, a férias remuneradas, ao lazer, ao bem-estar e à educação. Estão presentes nos artigos de no .22 a 27 da declaração de 1948. Por fim, os direitos de terceira geração inscrevem as condições políticas em 
que as duas primeiras gerações de direitos podem se realizar. Os direitos classificados nessa rubrica pressupõem que os Estados-nação nem sempre têm o poder de garantir as duas primeiras gerações de direitos. Por isso, esta terceira geração evoca a participação de entidades internacionais multilaterais, como a própria ONU, na garantia de tais direitos. São exemplos dos direitos de terceira geração: o direito à paz, ao meio ambiente e à autodeterminação. Segundo Weston (1985), estes são direitos coletivos e, por isso, requerem esforços multilaterais numa escala planetária. Para uma revisão do desenvolvimento da noção de direitos humanos na comunidade internacional, ver Weston (1985).

6. Caldeira (1992) faz um estudo da forma como a expressão direitos humanos esteve associada, por muito tempo, a "direito de bandido". Para ela, a formulação desse conceito foi resultado do lugar que a retórica da luta pelos direitos humanos no Brasil acabou tomando após a reconstituição do estado de direito. Ela sugere que a luta pelo fim da ditadura colocou na ordem do dia demandas pelo respeito aos direitos humanos dos presos políticos. Contudo, quando foi decretada a anistia, as organizações que os defendiam se voltaram para os presos comuns. Concomitantemente, houve, no caso de São Paulo, um aumento da criminalidade que levou as pessoas a se isolarem em nichos territoriais específicos, promovendo uma privatização do bem público, de forma que os direitos à segurança, àeducação, àsaúde, entre outros, passaram a ser considerados privilégios, mantidos com recursos privados, ao mesmo tempo em que os direitos humanos foram progressivamente associados aos "direitos de bandidos".

7. Para uma análise das trajetórias de alguns desses atores políticos na defesa e na promoção dos direitos humanos e da história da Comissão Teotônio Vilela, ver Tsunoda (2012).

8. A organização e a publicação do livro Brasil: nunca mais (1985) é exemplar do investimento e da ação política da Igreja Católica no Brasil na luta contra a ditadura e em promoção dos direitos humanos. Nesta obra é apresentado ao leitor todo o aparelho repressivo construído por parte do Estado para manter a ditadura. O livro é de autoria da Arquidiocese de São Paulo, em cuja sede funciona a Comissão Justiça e Paz, e foi organizado, inclusive, para pressionar o Estado brasileiro a assinar a Convenção contra a Tortura e outros Tratamentos ou Castigos Cruéis, Desumanos ou Degradantes, aprovada pela ONU em 10 de dezembro de 1984.

9. Destaca-se, contudo, que nem as convenções, nem os pactos têm força jurídica obrigatória e vinculadora.

10. Um panorama das diretrizes que orientavam as políticas do governo federal em relação às populações negras é apresentado no documento "Brasil/Presidência da República" (1998a).

11. Para uma discussão mais pormenorizada sobre os vários movimentos realizados pelo Estado brasileiro no reconhecimento do racismo no governo Fernando Henrique Cardoso, ver Silva (2000) e Bernardino (2002).

12. Embora na versão final do I PNDH os homossexuais de fato não apareçam enquanto segmento social para o qual são destinadas políticas públicas distintas, faz-se referência à homossexualidade nos seguintes trechos: "Direitos Humanos são os direitos fundamentais de todas as pessoas, sejam elas mulheres, negros, homossexuais, índios, idosos, portadores de deficiências, populações de fronteiras, estrangeiros e migrantes, refugiados, portadores de HIV, crianças e adolescentes, policiais, presos, despossuídos e os que têm acesso à riqueza. [...] Direitos Humanos referem-se a um sem-número de campos de atividade humana: o direito de ir e vir sem ser molestado [...] o direito de ser, pensar, crer e manifestar-se ou de amar sem tornar-se alvo de humilhações, discriminação ou perseguição. São aqueles direitos que garantem a existência digna de qualquer pessoa. [...] Propor legislação proibindo todo tipo de discriminação com base em origem, raça, etnia, sexo, idade, credo religioso, convicção política ou orientação sexual, e revogando normas discriminatórias na legislação infraconstitucional, de forma a reforçar e consolidar a proibição de práticas discriminatórias existentes na legislação constitucional" (Ministério da Justiça, 1998:45-6, 62). 
13. Para uma análise detalhada de tais protestos e das respostas do NEV para os mesmos, ver Silva (2000:85-97).

14. A fim de justificar a ausência de discriminação contra os homossexuais no I PNDH, Paulo Sérgio Pinheiro, em correspondência enviada a Luiz Mott/ABGLT, destacou justamente estes trechos do PNDH que coibiam a promoção de discriminação em razão de orientação sexual. Para Paulo Sérgio Pinheiro, tais assertivas internalizariam no programa as demandas apresentadas pela ABGLT e outras entidades. Esta sugestão, contudo, foi absolutamente refutada por Mott em correspondência seguinte.

15. O que hoje chamamos de Projeto Unesco consistiu em um programa de estudos realizado na década de 1950 no Brasil, em diferentes partes do país, a fim de identificar os fenômenos que teriam conformado a suposta democracia racial aqui existente, diante da agenda de combate ao racismo e promoção do desenvolvimento liderado por esta agência da ONU. Tratava-se de um esforço de pesquisa voltado à identificação de fenômenos que pudessem ser utilizados, no limite, como ferramentas no controle de conflitos internacionais e promoção da igualdade. Para uma discussão da importância do Projeto Unesco na formação intelectual de Fernando Henrique Cardoso e de outros intelectuais brasileiros, ver Ribeiro (2011). Para uma análise da importância do Projeto Unesco na formação e na consolidação das ciências sociais no Brasil, ver Maio (1999).

\section{ÍNDICE}

Keywords: Human rights, affirmative actions, nation building, recognition, global governance Palavras-chave: Direitos humanos, formação nacional, ações afirmativas, reconhecimento, governança global.

\section{AUTOR}

\section{KELLY SILVA}

UnB. Kelly Cristiane da Silva é professora do Departamento de Antropologia da Universidade de Brasília e pesquisadora Produtividade em Pesquisa do CNPq. É autora de As nações desunidas. Práticas da ONU e a estruturação do Estado em Timor-Leste (Editora UFMG, 2012), entre outras publicações, e líder do grupo de pesquisa intitulado "Processos de invenção, transposição e subversão da modernidade”. Endereço eletrônico: kellysa@uol.com.br 